\title{
Lung Progression GvHD
}

National Cancer Institute

\section{Source}

National Cancer Institute. Lung Progression GVHD. NCI Thesaurus. Code C126733.

Either a decrease by $10 \%$ predicted absolute value of $\%$ FEV1 or an NIH lung symptom score that has increased by 1 or more points, except 0 to 1 . 